\title{
Surface Activities, Antibacterial Activity and Corrosion Inhibition Properties of Gemini Quaternary Ammonium Surfactants with Amido Group and Carboxylic Counterions
}

\author{
Siqi Hu, Duojiao Fu, Hanyu Chen, Hongqin Liu* , and Baocai Xu
}

School of Light Industry, Beijing Key Laboratory of Flavor Chemistry, Beijing Higher Institution Engineering Research Center of Food Additives and Ingredients, Beijing Technology and Business University, No. 11 Fucheng Road, Beijing 100048, People's Republic of CHINA

\begin{abstract}
A series of gemini quaternary ammonium surfactants containing carboxylate counterion with the formula $\mathrm{C}_{17} \mathrm{H}_{35} \mathrm{CONH}\left(\mathrm{CH}_{2}\right)_{2} \mathrm{~N}^{+}\left(\mathrm{CH}_{3}\right)_{2}\left(\mathrm{CH}_{2}\right)_{2} \mathrm{~N}^{+}\left(\mathrm{CH}_{3}\right)_{2}\left(\mathrm{CH}_{2}\right)_{2} \mathrm{NHCO} \mathrm{C}_{17} \mathrm{H}_{35} \cdot 2 \mathrm{Y}\left(\mathrm{Y}_{3} \mathrm{HCOO}^{-}, \mathrm{CH}_{3} \mathrm{COO}^{-}\right.$, $\mathrm{CH}_{3} \mathrm{CHOHCOO}^{-}$) have been synthesized by a counterion conversion process and characterized by Fourier transform infrared spectroscopy and mass spectroscopy. It is found that these surfactants reduce the surface tension of water to a minimum value of $26.78 \mathrm{mN} \cdot \mathrm{m}^{-1}$ at a concentration of $1.21 \times 10^{-5} \mathrm{~mol} \cdot \mathrm{L}^{-1}$. TEM images reveal that aggregates with vesicles or tubular structure are spontaneously formed in these surfactants aqueous solution with the concentration of $1 \times 10^{-3} \mathrm{~mol} \cdot \mathrm{L}^{-1}$. It is also found that they are effective corrosion inhibitors for $A 3$ steel in acid solution and have superior antibacterial activity at a concentration of $0.1 \mathrm{~g} \cdot \mathrm{L}^{-1}$.
\end{abstract}

Key words: gemini quaternary ammonium surfactant, surface activity, antibacterial activity, corrosion inhibition

\section{Introduction}

Gemini surfactant has two lipophilic tail groups and hydrophilic head groups ${ }^{1)}$. Due to the unique chemical structure, gemini surfactant tends to form rather rich array of "self-assembled" structures in aqueous solution, including spherical micelle, ellipsoidal micelle, rodlike micelle, layered micelle, linear micelle, a membrane, vesicle, liquid crystals, sponge and other morphologies, and has better performance, such as low critical micelle concentration (CMC), high thermal stability, strong wettability, adhesion ability, and high surface reduction efficiency, etc ${ }^{2-6)}$. In recent years, cationic gemini surfactants especially gemini quaternary ammonium surfactants, which have shown enormous potential applications in various fields, covering detergents, cosmetics, textile dyeing, biotechnology, the pharmaceutical industry, food industry and the petroleum industry, have attracted wide attention from researchers ${ }^{6-8)}$.

Studies have shown that a gemini surfactant molecule with the requested properties to specific applications is possible to obtain by structure modification, such as changing its component, hydrophobic chain, counterion, spacer group length, spacer group softness and introducing specific functional groups ${ }^{9-13)}$. At present, some studies have reported the influence of positively charged counterions on surfactants, but the effect of negatively charged organic counterions on quaternary ammonium surfactants has rarely been reported ${ }^{14,15)}$. In addition, numerous studies have confirmed that the water solubility, biodegradability and the aggregation tendency of the surfactant could be increased by insertion of an amide bond in the surfactant molecule ${ }^{16,17)}$. Hoque et al. also demonstrated that surfactants with amido group had stronger surface activity than common hydrocarbon surfactants by small-angle neutron scattering and conductivity methods ${ }^{17)}$. So, in this paper, a series of gemini quaternary ammonium surfactants were synthesized by introducing amide functional groups and carboxylic counterions into the molecular structure. The surface properties, corrosion inhibition properties and bacteriostatic activity of them as well as the effect of the counterion were studied. To date, the anions of general gemini quaternary ammonium surfactants are mostly inorganic halogen atoms, which affect their properties and limit their application to a certain extent. The quaternary ammonium gemini surfactant without halogen counterions synthesized by the green chemical reagent dimethyl carbonate in this study meets the requirements of green

\footnotetext{
*Correspondence to: Hongqin Liu, School of Light Industry, Beijing Key Laboratory of Flavor Chemistry, Beijing Higher Institution Engineering Research Center of Food Additives and Ingredients, Beijing Technology and Business University, No. 11 Fucheng Road, Beijing 100048, People's Republic of CHINA E-mail: liuhongqin@ @th.btbu.edu.cn
} Accepted March 14, 2020 (received for review December 31, 2019) Journal of Oleo Science ISSN 1345-8957 print / ISSN 1347-3352 online http://www.jstage.jst.go.jp/browse/jos/ http://mc.manusriptcentral.com/jjocs 
chemistry.

\section{Experimental Procedures}

\subsection{Materials}

Methyl stearate, triethylenetetramine and dimethyl carbonate were of analytical grade and purchased from J\&K Scientific Ltd. Toluene, sodium hydroxide, formic acid, acetic acid, lactic acid, absolute ethanol, absolute methanol, absolute ethyl ether and acetonitrile were provided by Sinopharm chemical reagent Beijing Co., Ltd. Nutrient broth and benzalkonium chloride solution $\left(50 \mathrm{~g} \cdot \mathrm{L}^{-1}\right)$ were supplied by Beijing OBO biotech Co., Ltd and beijing Derun Pharmaceutical Co., Ltd, respectively. Pseudomonas aeruginosa, escherichia coli, staphylococcus aureus and bacillus subtilis were obtained from environmental professional laboratory. The high-purity water $\left(\rho=18.25 \mathrm{M} \Omega \cdot \mathrm{cm}^{-1}\right)$ was supplied by an ultrapure laboratory water purification system. N, N, N', N'- tetramethyl- N, N'-di-(2-stearylamideethyl) ethylenediamine methyl carbonate (purity $>$ $98 \%$ ) were prepared according to a green method reported in our previous paper.

\subsection{Synthesis of Gemini Surfactants (17-2-17-2Y)}

The 17-2-17-2Y gemini surfactants were synthesized according to the method reported in our previous paper ${ }^{13,18)}$. The general formula and synthesis procedure for the 17-2$17-2 Y$ surfactants were shown in Scheme 1. Their purity was great than $98 \%$ and the yield values were 90.5 $92.4 \%$. Owing to the carboxylic counterion of the surfactants, the $\mathrm{pH}$ values of the following experimental systems (measurement of surface tension, dynamic light scattering and antibacterial activity) are all about 6 .

\subsection{Confirmation of Structure}

Mass spectroscopy (MS) and Fourier transform infrared (FTIR) analysis of the synthesized gemini surfactants were performed using AB SCIEX API3200 LC/MS spectrometer and Thermo Fisher Nicolet ISLO FTIR spectrometer, respectively.

\subsection{Measurement of Surface Tension}

At $25^{\circ} \mathrm{C}$, the static surface tension of these gemini surfactants aqueous solution within a concentration range of 1 $\times 10^{-7}-1 \times 10^{-2} \mathrm{~mol} \cdot \mathrm{L}^{-1}$ was measured on a Dataphysics tensiometer DCAT11 by the Wilhemy plate method.

\subsection{Measurement of Dynamic Light Scattering (DLS)}

The size distributions of self-assembled aggregate measurements were performed with Malvern Zetasizer Nano $\mathrm{ZS}$ instrument at $25^{\circ} \mathrm{C}$ with a solid state He-Ne laser (output power of $22 \mathrm{~mW}$ at $\lambda=632.8 \mathrm{~nm}$ ) as a light source. The scanning scattering angle was set as $173^{\circ}$. Each sample with the concentration of $1 \times 10^{-3} \mathrm{~mol} \cdot \mathrm{L}^{-1}$ equilibrated for 2 min before measurements, and then was measured at least three times. The distribution of diffusion coefficients $(D)$ of the solutes was obtained by analyzing the correlation function of scattering data using CONTIN method. Then the apparent equivalent hydrodynamic radius $\left(R_{h}\right)$ was calculated from Stokes-Einstein equation $R_{h}$ $=k T / 6 \pi \eta D$, where $k$ was the Boltzmann constant, $T$ was the absolute temperature, and $\eta$ was the solvent viscosity.

\subsection{Transmission Electron Microscope (TEM)}

The TEM sample was prepared as followes: (I)a drop of surfactant aqueous solution with the concentration of $1 \times$ $10^{-3} \mathrm{~mol} \cdot \mathrm{L}^{-1}$ was dropped onto the clean sealing film; (II) porous carbon support membrane (260 mesh) was put upside down on the surface of the droplet for $10 \mathrm{~min}$; (III) excess of the droplet was sucked from the edge; (IV) the porous carbon support membrane was dried for at least 12 $\mathrm{h}$ in a vacuum dryer; (V) a drop of $1 \%$ dioxyuranium acetate was added to another clean sealing film, then the adsorbed carbon support membrane was put upside down on it and dyed for $15 \mathrm{~s}$; (VI) the porous carbon support

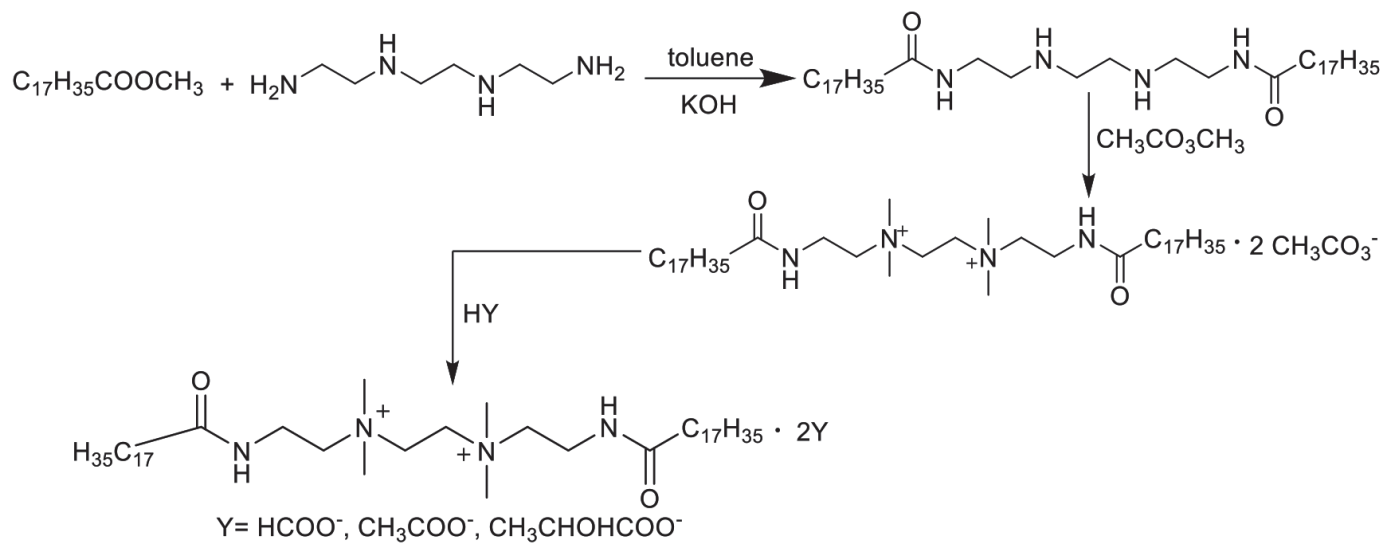

Scheme 1 Synthesis of 17-2-17-2Y. 
membrane was dried for at least $12 \mathrm{~h}$ in a vacuum dryer. TEM measurements were made using the Oxford X-MAX JEM-2100 operating at an accelerating voltage of $120 \mathrm{kV}$ by a negative-staining method.

\subsection{Antibacterial Activity Measurement}

Antibacterial activities of these surfactants were determined by monitoring the growth of Gram-negative bacteria (Pseudomonas aeruginosa and Escherichia coli) and Grampositive bacteria (Staphylococcus aureus and Bacillus Subtilis) using Finland Bioscreen automatic growth curve instrument. $200 \mu \mathrm{L}$ bacteria was introduced to the fluid nutrient broth, which was prepared by mixing $1.8 \mathrm{~g}$ nutrient broth powder and $100 \mathrm{~mL}$ distilled water and was sterilized by autoclave. After cultivating for $12 \mathrm{~h}$ with oscillation at $37{ }^{\circ} \mathrm{C}, 200 \mu \mathrm{L}$ bacterial suspension was taken out and added to the other freshly prepared sterilized fluid nutrient broth, and oscillated continuously for $6 \mathrm{~h}$ to completely motivate the bacteria.

The baseline group consisted of $50 \mu \mathrm{L}$ sterile water and $450 \mu \mathrm{L}$ blank nutrient. $50 \mu \mathrm{L}$ benzalkonium chloride solution with a concentration of $1.00 \mathrm{~g} \cdot \mathrm{L}^{-1}$ was mixed with 450 $\mu \mathrm{L}$ bacterial solution to set as the control group. The blank group was prepared by mixing $50 \mu \mathrm{L}$ sterile water with 450 $\mu \mathrm{L}$ bacterial solution. $50 \mu \mathrm{L}$ surfactants solution with a concentration gradient of 0.50 and $1.00 \mathrm{~g} \cdot \mathrm{L}^{-1}$ prepared by sterile water was mixed with $450 \mu \mathrm{L}$ bacterial solution to prepare the experimental group. The prepared solution was separately placed into the middle part of the 100-well plates and monitored for $24 \mathrm{~h}$ with oscillation at $37^{\circ} \mathrm{C}$, then the optical density (OD) value at $600 \mathrm{~nm}$ was measured every other hour.

\subsection{Corrosion inhibition measurements}

The corrosion inhibition of these surfactants for A3 steel $\left(\rho=7.86 \mathrm{~g} \cdot \mathrm{cm}^{-3}\right)$ in $6.00 \mathrm{wt} \% \mathrm{HCl}$ at $298.15 \mathrm{~K}$ was investigated using the weight loss method. A3 steel specimens (50 $\times 25 \times 2 \mathrm{~mm}$ ), which were first wiped clean with filter paper and then degreased by placed in petroleum ether, were soaked in anhydrous ethanol for 5 min and dried with cold wind, and were stored in a desiccator for $1 \mathrm{~h}$. After that, the specimens were accurately weighted to $0.1 \mathrm{mg}$. Then 3 parallel specimens were immersed in the $6.00 \mathrm{wt} \%$ $\mathrm{HCl}$ solutions with and without addition of different concentrations of surfactants with stirring at $298.15 \mathrm{~K}$. After 6 $\mathrm{h}$, the specimens were removed, rinsed with water, further soaked in acid pickling liquid for $5 \mathrm{~min}$, rinsed again with water, put into $5.66 \mathrm{wt} \% \mathrm{NaOH}$ solution for $30 \mathrm{~s}$, rinsed with distilled water, and immersed in ethanol for $5 \mathrm{~min}$. After that, they were taken out, first placed on filter paper to dry in cold air, then in a desiccator to dry for $1 \mathrm{~h}$, at last accurately weighted to $0.1 \mathrm{mg}$.

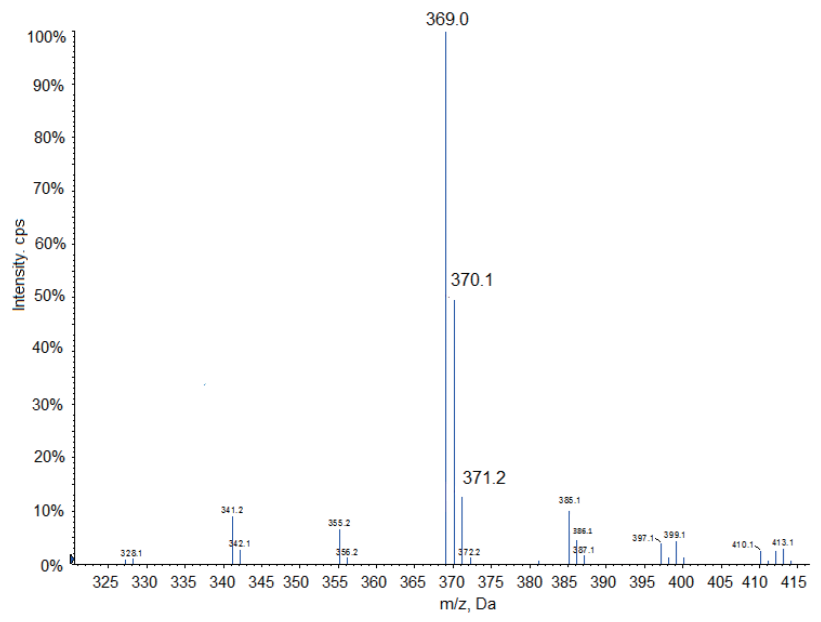

Fig. 1 Cationic scanning mass spectra of $17-2-17-2 \mathrm{HCOO}^{-}$.

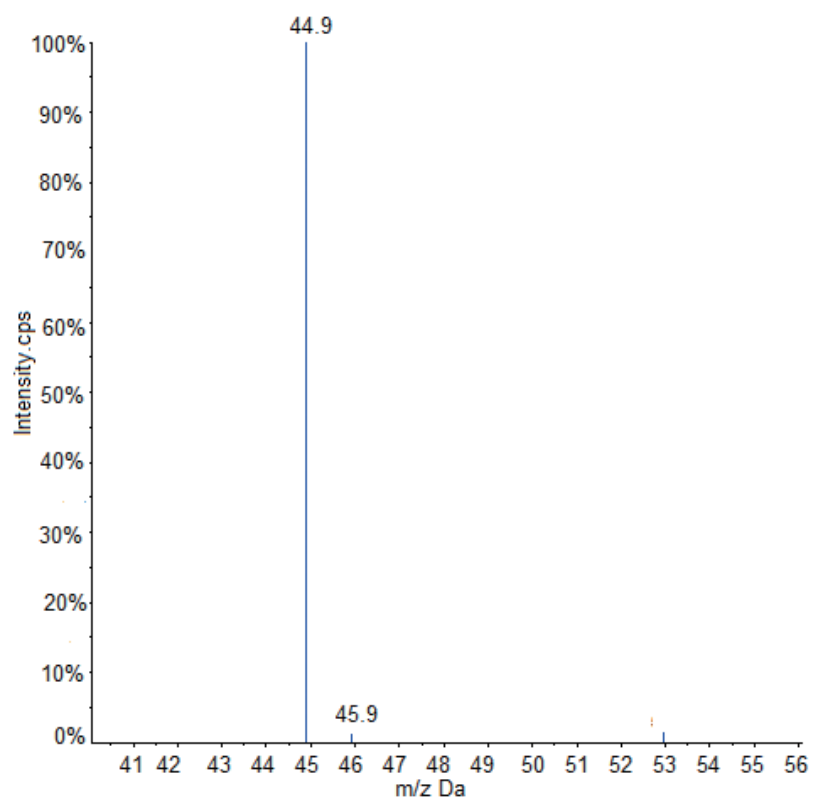

Fig. 2 Anion scanning mass spectra of 17-2-17-2 $\mathrm{HCOO}^{-}$.

\section{Results and Discussion}

3.1 Characterization of gemini quaternary ammonium surfactants

The detailed characterization of all the surfactants was done by mass spectroscopy and Fourier transform infrared spectroscopy. The Mass spectra and FTIR spectra of the representative compound 17-2-17-2 $\mathrm{HCOO}^{-}$were shown in Figs. 1-3. Spectral characterizations results were as follows. In brief, their structures were confirmed.

17-2-17-2HCOO ${ }^{-}$: Mass Spectra: Cationic scanning $M / E$ : 369.0; Anion scanning $M / E$ : 44.9; FTIR Spectra $\left(\mathrm{KBr}, \mathrm{v}, \mathrm{cm}^{-1}\right)$ : 3395.18, 3304.94(N-H), 2917.89, 2849.85(C-H), 1647.12 (C = O), 1558.60, 1260.05 (C-N, N-H coupling), 1470.89 (C-H), $1420.32(\mathrm{COO}), 720.97(\mathrm{C}-\mathrm{H})$.

17-2-17-2 $\mathrm{CH}_{3} \mathrm{COO}^{-}$: Mass Spectra: Cationic scanning $M /$ E: 369.0; Anion scanning $M / E$ : 58.9; FTIR Spectra (KBr, v, 


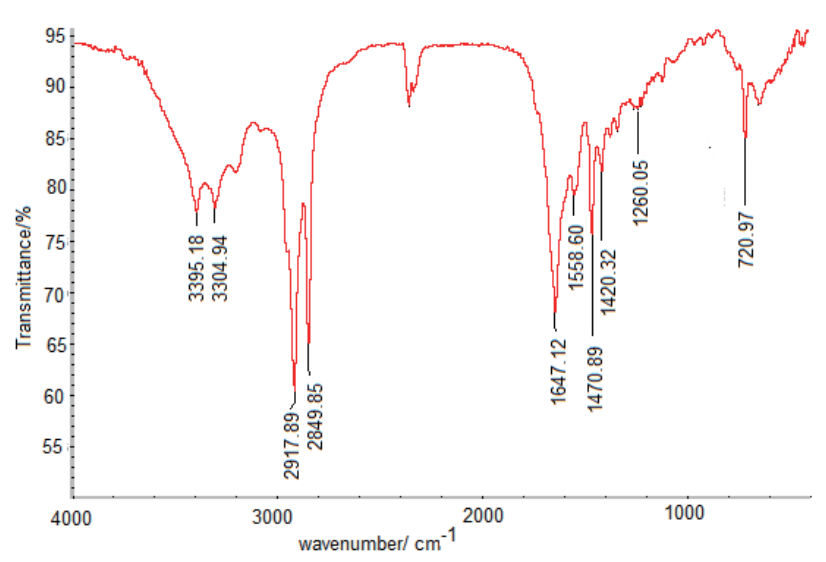

Fig. 3 FTIR spectra of $17-2-17-2 \mathrm{HCOO}^{-}$.

$\left.\mathrm{cm}^{-1}\right): 3305.39(\mathrm{~N}-\mathrm{H}), 2919.32,2850.68(\mathrm{C}-\mathrm{H}), 1651.52(\mathrm{C}$ =O), $1558.54,1264.12(\mathrm{C}-\mathrm{N}, \mathrm{N}-\mathrm{H}$ coupling $), 1467.92$ (C-H), 1420.28(COO), $721.77(\mathrm{C}-\mathrm{H})$.

17-2-17-2 $\mathrm{CH}_{3} \mathrm{CHOHCOO}^{-}$: Mass Spectra: Cationic scanning $M / E$ : 369.0; Anion scanning $M / E$ : 88.9; FTIR Spectra $\left(\mathrm{KBr}, \mathrm{v}, \mathrm{cm}^{-1}\right): 3339.03(\mathrm{~N}-\mathrm{H}), 2923.18,2853.20(\mathrm{C}-\mathrm{H})$, $1654.32(\mathrm{C}=\mathrm{O}), 1541.31,1224.48(\mathrm{C}-\mathrm{N}, \mathrm{N}-\mathrm{H}$ coupling), $1462.72(\mathrm{C}-\mathrm{H}), 1373.18(\mathrm{COO}), 1130.42(-\mathrm{OH}), 1031.75$ (C-OH).

\subsection{Surface activity}

In Fig. 4, surface tension $(\gamma)$ is plotted against the concentration $(c)$ of these surfactant aqueous solutions. The CMC values determined by the inflection point of the $\gamma-c$ curve and the surface tension at the $\operatorname{CMC}\left(\gamma_{\mathrm{CMC}}\right)$ acquired by analyzing the plateau region of the plots are summarized in Table 1. As is seen in Table 1, the $\gamma_{\mathrm{CMC}}$ values of these gemini quaternary ammonium surfactants are between 26.78 and $28.12 \mathrm{mN} \cdot \mathrm{m}^{-1}$, suggesting higher surface activities. Table 1 shows that the $\gamma_{\mathrm{CMC}}$ values are in the range of $1.21 \times 10^{-5}$ to $2.54 \times 10^{-5} \mathrm{~mol} \cdot \mathrm{L}^{-1}$, which are lower than some of other gemini surfactants, indicating that these double-chain compounds aggregate more easily to form micelles. In addition, the CMC and $\gamma_{\mathrm{CMC}}$ values of these surfactants increase with the alkyl chain length of carboxylic counterions increase. It is because the hydrophilicity of counterions affects the micellization of the surfactants. The higher the hydrophilicity of counterions, the more unfavorable the micellization is, the higher the CMC will be ${ }^{19)}$.

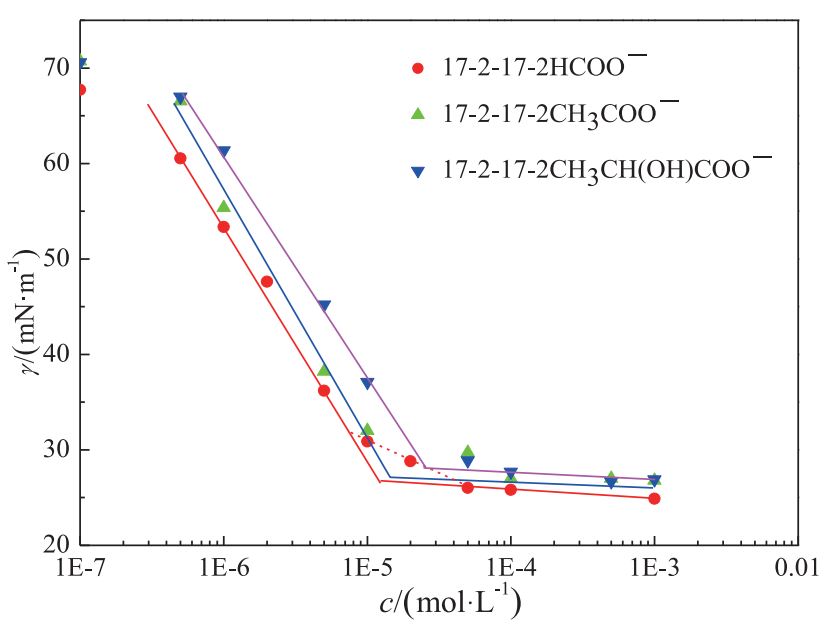

Fig. 4 Plots of $\gamma$ against the concentration (c) of 17-2-17$2 \mathrm{Y}$ at $25^{\circ} \mathrm{C}, \mathrm{Y}=\mathrm{HCOO}^{-}(\mathbf{O}), \mathrm{CH}_{3} \mathrm{COO}^{-}(\boldsymbol{\Delta})$, $\mathrm{CH}_{3} \mathrm{CHOHCOO}^{-}(\boldsymbol{\nabla})$.

The maximum surface excess concentration $\left(\Gamma_{\max }\right)$ and the minimum area per surfactant molecule $\left(A_{\text {min }}\right)$ adsorbed at the air-aqueous solution interface, which are listed in Table 1, are calculated according to the Gibbs adsorption equations $^{20)}$ :

$$
\begin{aligned}
\Gamma_{\max } & =\left(\frac{-1}{2.303 n R T}\right)\left(\frac{d \gamma}{d \log c}\right) \\
A_{\min } & =\frac{1}{N_{A} \Gamma_{\max }}
\end{aligned}
$$

where $R$ is the gas constant, $N_{A}$ is Avogadro's number, $T$ is the absolute temperature, and $n$ is a constant. For gemini quaternary ammonium surfactants, the value of n, which has no effect on the variation trend of the values of $\Gamma_{\max }$ and $A_{\text {min }}$, is generally determined as 2 or $3^{21,22)}$. However, some reports have suggested that it is more appropriate to use a value of 2 for $n$, because $n$ is 3 , the calculated $A_{\min }$ is unacceptably large $^{23)}$. In this case, $n$ is taken as 2 . Table 1 shows that these three species of carboxylic counterions have little effect on the values of $\Gamma_{\max }$ and $A_{\min }$. The reason may be that, these short alkyl chain counterions such as formic acid and acetate have strong hydrophilicity and weak hydrophobicity, will not or seldom insert into the surface adsorption layer, thus the surface adsorption parameters of these gemini quaternary ammonium surfactants have little change ${ }^{13)}$.

Table 1 Characteristic Parameters of 17-2-17-2Y Aqueous Solutions at 298.15 K.

\begin{tabular}{lcccc}
\hline \multicolumn{1}{c}{ Gemini surfactant } & $\begin{array}{c}\mathrm{CMC} \\
\left(\mathrm{mol} \cdot \mathrm{L}^{-1}\right)\end{array}$ & $\begin{array}{c}\gamma_{C M C} \\
\left(\mathrm{mN} \cdot \mathrm{m}^{-1}\right)\end{array}$ & $\begin{array}{c}\Gamma_{\max } \\
\left(\times 10^{-10} \mathrm{~mol} \cdot \mathrm{cm}^{-2}\right)\end{array}$ & $\begin{array}{c}A_{\min } \\
\left(\mathrm{nm}^{2}\right)\end{array}$ \\
\hline $17-2-17-2 \mathrm{HCOO}^{-}$ & $1.21 \times 10^{-5}$ & 26.78 & 2.13 & 0.78 \\
$17-2-17-2 \mathrm{CH}_{3} \mathrm{COO}^{-}$ & $1.44 \times 10^{-5}$ & 27.15 & 2.29 & 0.73 \\
$17-2-17-2 \mathrm{CH}_{3} \mathrm{CHOHCOO}^{-}$ & $2.54 \times 10^{-5}$ & 28.12 & 2.02 & 0.82 \\
\hline
\end{tabular}




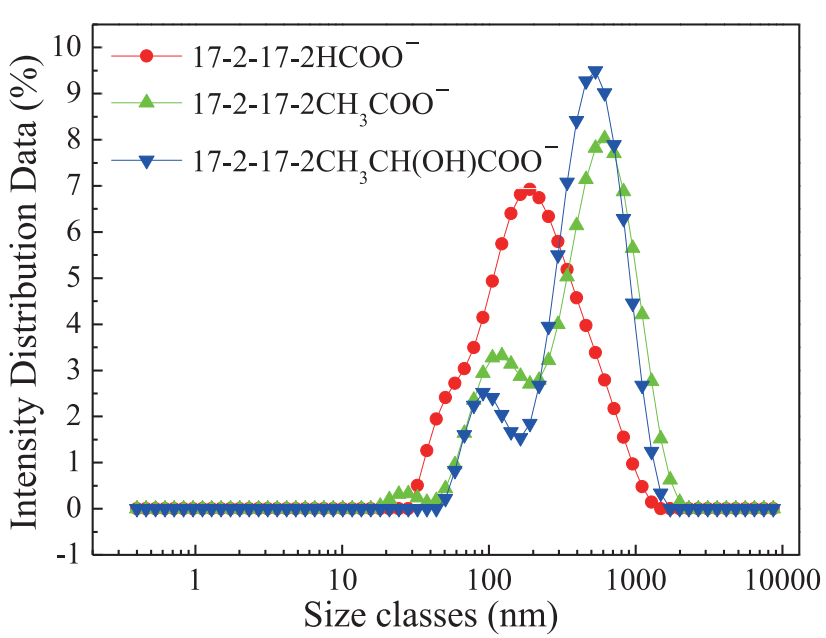

Fig. $5 R_{h}$ distribution of 17-2-17-2Y, $\mathrm{Y}=\mathrm{HCOO}^{-}$ $\mathrm{CH}_{3} \mathrm{COO}^{-}(\boldsymbol{\Delta})$, and $\mathrm{CH}_{3} \mathrm{CHOHCOO}^{-}(\boldsymbol{\nabla})$ in aqueous solution with the concentration of $1 \times 10^{-3}$ $\mathrm{mol} \cdot \mathrm{L}^{-1}$.

\subsection{DLS and TEM measurments}

The sizes and distributions of the aggregates formed in these surfactants aqueous solution with the concentration of $1 \times 10^{-3} \mathrm{~mol} \cdot \mathrm{L}^{-1}$ are investigated by DLS. Seen from Fig. 5, the $R_{h}$ values of these surfactant solutions are distributed in the range of $40-2000 \mathrm{~nm}$. In addition, at least two hydrated radius distribution peaks were observed in these surfactants solutions, although the first peak of 17-2$17-2 \mathrm{HCOO}^{-}$is not obvious. The peak near 100 nanometers may correspond to micro vesicles, and the peak of hun- dreds of nanometers may be assigned to more complex aggregates, such as multilamellar vesicles, tubular micelle, lamellar micelle, etc. Correspondingly, the morphology of aggregates of these gemini surfactants in aqueous solution with the concentration of $1 \times 10^{-3} \mathrm{~mol} \cdot \mathrm{L}^{-1}$ have been studied by TEM measurement. The results are shown in Fig. 6.

Figure 6 shows that the size of these aggregates is practically consistent with the results of DLS. The mixed micelles of spheroidal vesicles and longish tubular structure are observed in aqueous solution of $17-2-17-2 \mathrm{HCOO}^{-}$(Fig. $6 \mathrm{I})$, the mixture of single-room vesicles and multicenter vesicles (Fig. 6II) are formed in the case of 17-2-17$2 \mathrm{CH}_{3} \mathrm{COO}^{-}$, and there mainly exists some longish tubular structure aggregates for $17-2-17-\mathrm{CH}_{3} \mathrm{CH}(\mathrm{OH}) \mathrm{COO}^{-}$(Fig. 6 III). It can draw a conclusion that the counterions have little influence on the self-assembly behavior of these surfactants at a high concentration. The formation of various micelles is mainly due to the self-organization of quaternary ammonium cation driven by entropy. Hydrogen bonds between amide groups near the hydrophilic headgroups region can minimize the repulsive interactions among quaternary ammonium groups, which can further stable the micelles.

\subsection{Measurements of antibacterial activity}

The bacteriostatic efficiency is calculated according to the following formula:

$$
X=\frac{\left(O D_{0}-O D_{1}\right)}{O D_{0}} \times 100 \%
$$
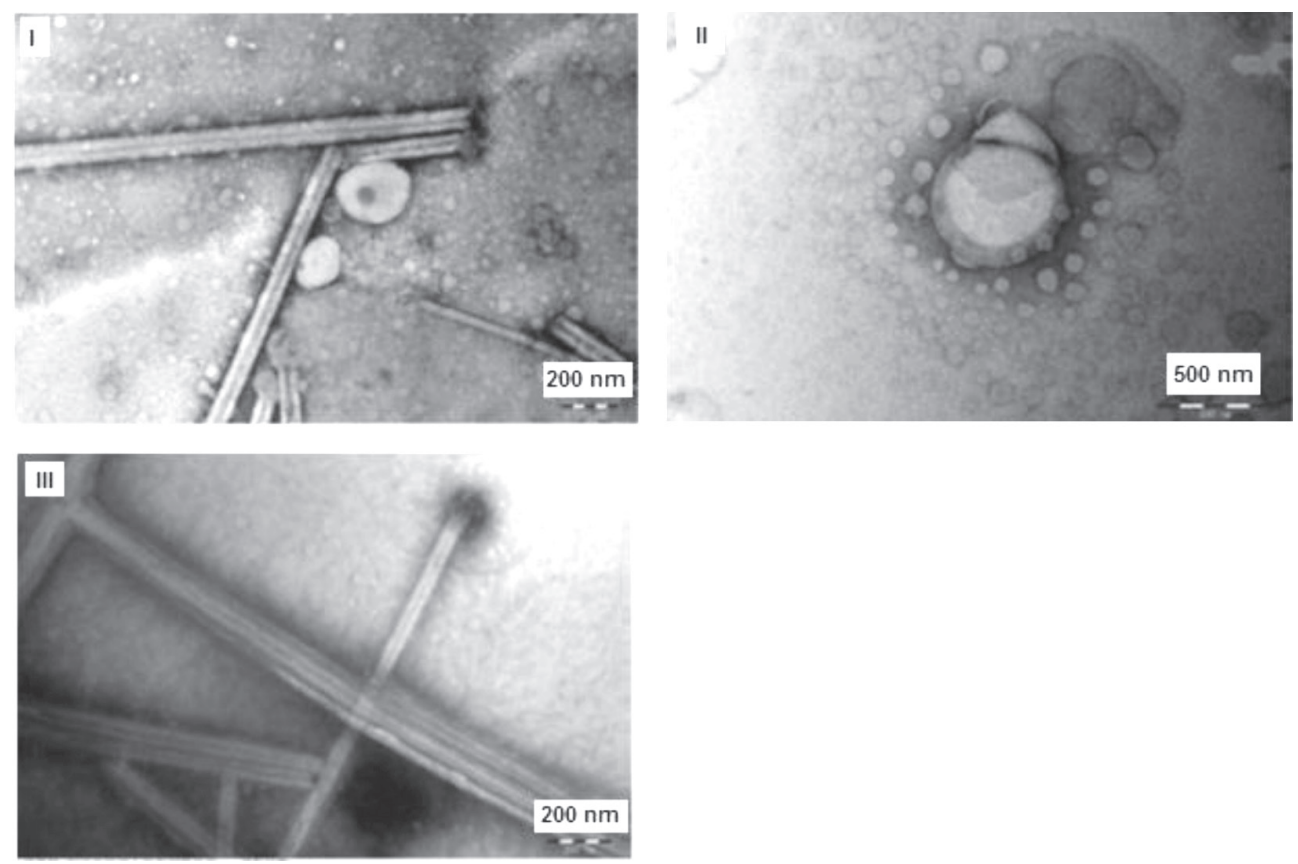

Fig. 6 TEM micrographs of 17-2-17-2Y, I: $\mathrm{Y}=\mathrm{HCOO}^{-}$, II: $\mathrm{CH}_{3} \mathrm{COO}^{-}$, and III: $\mathrm{CH}_{3} \mathrm{CHOHCOO}^{-}$in aqueous solution of the concentration of $1 \times 10^{-3} \mathrm{~mol} \cdot \mathrm{L}^{-1}$. 
where $\mathrm{OD}_{0}$ and $\mathrm{OD}_{1}$ refer to the $\mathrm{OD}$ values of the bacillus without surfactants and with surfactants at the same time, respectively. According to our previous work ${ }^{13)}$, the values at $15 \mathrm{~h}$ are used to evaluate the surfactant inhibition for Pseudomonas aeruginosa and Staphylococcus aureus, while the values at $10 \mathrm{~h}$ and $12 \mathrm{~h}$ are used to evaluate for Escherichia coli and Bacillus subtilis, respectively. The bacteriostatic efficiency of these gemini surfactants solution and $0.1 \mathrm{~g} \cdot \mathrm{L}^{-1}$ benzalkonium chloride solution are listed in Table 2. The date presented in Table 2 shows that the antibacterial activities of most of these gemini surfactants with the concentration of $0.05 \mathrm{~g} \cdot \mathrm{L}^{-1}$ is better than that of $0.1 \mathrm{~g} \cdot \mathrm{L}^{-1}$ benzalkonium chloride solution. At the concentration of $0.1 \mathrm{~g} \cdot \mathrm{L}^{-1}$, their bacteriostatic efficiency to Gram-positive and Gram-negative bacteria is more than $85 \%$, indicting excellent bacteriostatic effect. Table 2 also shows that the variation trend of bacteriostatic effect to the same bacteria of ammonium formate, ammonium acetate, and ammonium lactate with the same concentration is gradually decreasing. Sterilization is due to the adsorption and penetration of surfactant molecules at the microbial surface. The counterions wrapped with the positive micelles are diffused manner, gemini surfactants with shorter alkyl chain length of counterions have larger diffusion region and can prevent the bacteria from exchanging substances with the nutrient medium better.

\subsection{Corrosion inhibition}

Surfactant molecules adsorb on the metals by electrostatic and chemical adsorption to form a protective layer blocking the active corrosion sites, thereby delaying the corrosion of the metal. The following equation is used to calculate the inhibition efficiency $\eta$ of these gemini surfactants for the corrosion of A3 steel specimen:

$$
\eta=\frac{\Delta m_{0}-\Delta m_{1}}{\Delta m_{0}} \times 100 \%
$$

where $\Delta m_{0}$ and $\Delta m_{1}$ are the weight loss of the steel speci-

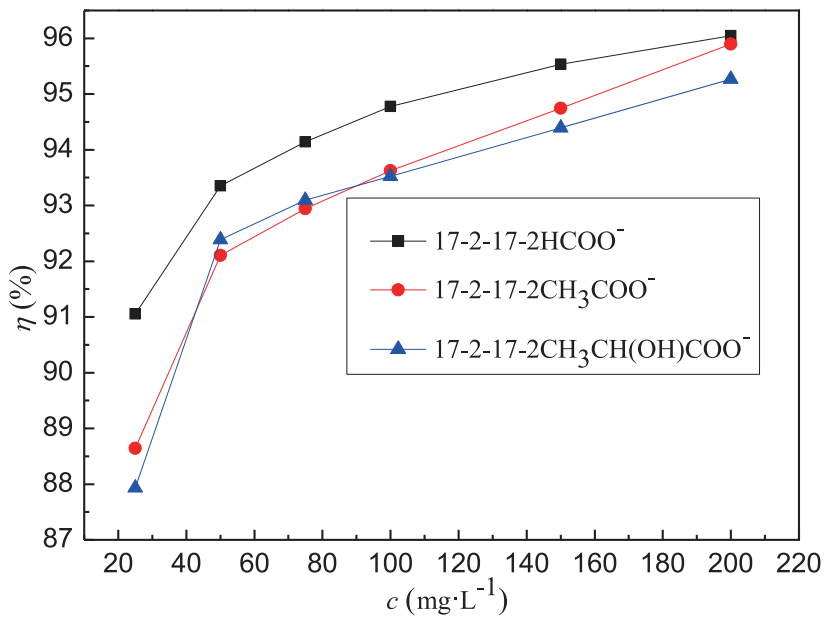

Fig. 7 Plots of inhibition efficiencies against the mass concentration of 17-2-17-2Y ( $\mathrm{Y}=\mathrm{HCOO}^{-}, \mathrm{CH}_{3} \mathrm{COO}^{-}$, and $\mathrm{CH}_{3} \mathrm{CHOHCOO}^{-}$) at $298.15 \mathrm{~K}$.

mens after immersion in solutions without and with inhibitor, respectively. Figure 7 presents the variation of $\eta$ versus the concentration. Figure 7 shows that $\eta$ increases with the surfactants concentration increases, and a significant inflection point appears. After the inflection point, $\eta$ increases slowly and tends to be stable, indicating the surfactant molecules have already formed a saturated adsorption in the steel surface. In addition, at the infection point, $\eta$ values of these three surfactants are more than $90 \%$, suggesting they are effective.

Figure 7 also shows that there is a little change in inhibition efficiency of ammonium formate, ammonium acetate, and ammonium lactate. Moreover, their inhibition efficiency is higher than that of $17-2-17-2 \mathrm{CH}_{3} \mathrm{CO}_{3}{ }^{-}$. Yousefi et al. suggested that counterions can form an intermediate bond between the metal surface and the hydrophilic head group to increase the adsorption on the metal surface ${ }^{24)}$. The stronger the hydrophilicity of the counterion is, the stron-

Table 2 The Bacteriostatic Efficiency of 17-2-17-2Y $\left(\mathrm{Y}=\mathrm{HCOO}^{-}, \mathrm{CH}_{3} \mathrm{COO}^{-}\right.$, and $\left.\mathrm{CH}_{3} \mathrm{CHOHCOO}^{-}\right)$at different concentration $\left(\mathrm{g} \cdot \mathrm{L}^{-1}\right)$ at $37^{\circ} \mathrm{C}$.

\begin{tabular}{cccccc}
\hline \multirow{2}{*}{ Bacteriostatic efficiency } & \multicolumn{3}{c}{ Gemini surfactant } \\
\cline { 2 - 5 } & & $\begin{array}{c}17-2-17- \\
2 \mathrm{HCOO}^{-}\end{array}$ & $\begin{array}{c}17-2-17- \\
2 \mathrm{CH}_{3} \mathrm{COO}^{-}\end{array}$ & $\begin{array}{c}17-2-17- \\
2 \mathrm{CH}_{3} \mathrm{CH}(\mathrm{OH}) \mathrm{COO}^{-}\end{array}$ & $\begin{array}{c}\text { Benzalkonium } \\
\text { chloride }\end{array}$ \\
\hline Pseudomonas & 0.05 & $87.3 \%$ & $80.8 \%$ & $73.4 \%$ & $/$ \\
aeruginosa (\%) & 0.1 & $91.2 \%$ & $88.6 \%$ & $86.0 \%$ & $76.0 \%$ \\
Escherichia & 0.05 & $82.3 \%$ & $79.3 \%$ & $81.0 \%$ & $/$ \\
coli (\%) & 0.1 & $92.8 \%$ & $91.7 \%$ & $89.7 \%$ & $74.0 \%$ \\
Staphylococcus & 0.05 & $83.4 \%$ & $82.5 \%$ & $80.2 \%$ & $/$ \\
aureus (\%) & 0.1 & $94.0 \%$ & $93.1 \%$ & $91.8 \%$ & $79.0 \%$ \\
Bacillus & 0.05 & $85.6 \%$ & $81.2 \%$ & $78.8 \%$ & $/$ \\
subtilis (\%) & 0.1 & $92.5 \%$ & $90.9 \%$ & $88.7 \%$ & $74.0 \%$ \\
\hline
\end{tabular}


ger the binding force with the hydrophilic head group is, thus forming a better protection. In addition, these surfactants can also react with the corrosive medium to reduce the acidity of the corrosive medium, thereby increasing the corrosion inhibition efficiency.

\section{Conclusion}

In summary, three gemini quaternary ammonium surfactants with carboxylic counterions are synthesized. Studies have shown that the CMC values of these surfactants are $1.21 \times 10^{-5} \sim 2.54 \times 10^{-4} \mathrm{~mol} \cdot \mathrm{L}^{-1}$, and the $\gamma_{\mathrm{CMC}}$ values are 26.78 $28.12 \mathrm{mN} \cdot \mathrm{m}^{-1}$, suggesting their higher surface activities. With an increase of the alkyl chain length of the carboxylic counterions, the CMC and $\gamma_{\text {CMC }}$ values of these surfactants increase, and the values of $\Gamma_{\max }$ and $A_{\min }$ have little difference. Meanwhile, the DLS and TEM results show that that aggregates with vesicles or tubular structure, the $R_{h}$ values of which are distributed in the range of 40-2000 $\mathrm{nm}$, are spontaneously formed in these surfactants aqueous solution with the concentration of $1 \times 10^{-3} \mathrm{~mol} \cdot \mathrm{L}^{-1}$. These gemini surfactants are also found to have superior antibacterial activity at a concentration of $0.1 \mathrm{~g} \cdot \mathrm{L}^{-1}$, and the variation trend of bacteriostatic effect to the same bacteria of ammonium formate, ammonium acetate, and ammonium lactate with the same concentration is gradually decreasing. Furthermore, they are also effective corrosion inhibitors for A3 steel in acid solution.

\section{Acknowledgment}

The work was supported by National Key R\&D Program of China(2017YFB0308701), the National Natural Science Foundation of China (21676003), Beijing Municipal Science and Technology Project(Z171100001317015), the Science and Technology Program Key Project of Beijing Municipal Commission of Education(KZ201510011010), the Transformation of Scientific and Technological AchievementsPromotion Plan Project(PXM2016_014213 000028).

\section{References}

1) Menger, F.M.; Keiper, J.S. Gemini surfactants. Angew. Chem., Int. Ed. 39, 1906-1920(2000).

2) Zhang, S.S.; Yu, J.; Wu, J.Z.; Tong, W.; Lei, Q.F.; Fang, W.J. Micellization parameters of six Gemini quaternary ammonium surfactants from measurements of conductivity and surface tension. J. Chem. Eng. Data. 59, 2891-2900 (2014).

3) Fan, Y.X.; Han, Y.C.; Wang, Y.L. Effects of molecular structures on aggregation behavior of gemini surfac- tants in aqueous solutions. Acta Phys.-Chim. Sin. 32, 214-226 (2016).

4) Sharma, R.; Kamal, A.; Abdinejad, M.; Mahajan, R.K.; Kraatz, H.-B. Advances in the synthesis, molecular architectures and potential applications of gemini surfactants. Adv. Colloid Interface Sci. 248, 35-68 (2017).

5) Garcia, M.T.; Kaczerewska, O.; Ribosa, I.; Brycki, B.; Materna, P.; Drgas, M. Hydrophilicity and flexibility of the spacer as critical parameters on the aggregation behavior of long alkyl chain cationic gemini surfactants in aqueous solution. J. Mol. Liq. 230, 453-460 (2017).

6) Zhang, S.S.; Ding, S.P.; Yu, J.; Chen, X.R.; Lei, Q.F.; Fang, W.J. Antibacterial activity, in vitro cytotoxicity, and cell cycle arrest of gemini quaternary ammonium surfactants. Langmuir 31, 12161-12169 (2015).

7) Tiecco, M.; Cardinali, G.; Roscini, L.; Germani, R.; Corte, L. Biocidal and inhibitory activity screening of de novo synthesized surfactants against two eukaryotic and two prokaryotic microbial species. Colloids Surf. B 111, 407-417 (2013).

8) Tavano, L.; Infante, M.R.; Riya, M.A.; Pinazo, A.; Vinardell, M.P.; Mitjans, M.; Manresa, M.A.; Perez, L. Role of aggregate size in the hemolytic and antimicrobial activity of colloidal solutions based on single and gemini surfactants from arginine. Soft Matter 9, 306319 (2013).

9) Xu, X.J.; Guo, J.W.; Zhong, X. Synthesis and properties of dissymmetric gemini surfactants with adamantane spacer. Chin. Chem. Lett. 25, 367-369(2014).

10) Xu, D.Q.; Pan, Z.W. Phase-transfer catalysis of a new cationic gemini surfactant with ester groups for nucleophilic substitution reaction. Chin. Chem. Lett. 25, 1169-1173(2014).

11) Avinash, B.; Rekha, G.S.; Setsuko, K.; Takeshi, E.; Kenichi, S.; Masahiko, A.; Hideki, S. Self-aggregation properties of new ester-based gemini surfactants and their rheological behavior in the presence of cosurfactant-monolaurin. Colloids Surf. A 461, 258-266 (2014).

12) Gao, X.R. Wang, Y.; Zhao, X.X.; Wei, W.L.; Chang, H.H. Equilibrium and dynamic surface tension properties of gemini quaternary ammonium salt surfactants with ester groups. Colloids Surf. A 509, 130-139(2016).

13) Zhou, X.Q.; Hu, S.Q.; Wang, Y.; Ullah, S.; Hu, J.; Liu, H.Q.; Xu, B.C. The surface adsorption, aggregate structure and antibacterial activity of gemini quaternary ammonium surfactants with carboxylic counterions. Royal Society Open Science 6, 190378(2019).

14) Wang, C.Y.; Morgner, H. The dependence of surface tension on surface properties of ionic surfactant solution and the effects of counterions therein. Phys. Chem. Chem. Phys. 16, 23386-23393(2014).

15) Benrraou, M.; Bales, B.L.; Zana, R. Effect of the nature 
of the counterion on the properties of anionic surfactants. 1. CMC, ionization degree at the CMC and aggregation number of micelles of sodium, cesium, tetramethylammonium, tetraethylammonium, tetrapropylammonium, and tetrabutylammonium dodecyl sulfates. J. Phys. Chem. B 107, 13432-13440 (2003).

16) Stjerndahl, M.; Holmberg, K. Synthesis, stability, and biodegradability studies of a surface-active amide. $J$. Surfact. Deterg. 8, 331-337 (2005).

17) Hoque, J.; Gonuguntla, S.; Yarlagadda, V.; Aswal, V.K.; Haldar, J. Effect of amide bonds on the self-assembly of gemini surfactants. Phys. Chem. Chem. Phys. 16, 11279-11288(2014).

18) Liu, H.Q.; Zhou, X.Q.; Zhang, X.X.; Shi, G.Y.; Hu, J.; Liu, C.Y.; Xu, B.C. Green synthesis, surface activity, micellar aggregation, and corrosion inhibition properties of new gemini quaternary ammonium surfactants. J. Chem. Eng. Data 63, 1304-1315(2018).

19) Manet, S.; Karpichev, Y.; Bassani, D.; Kiagus-Ahmad, R.; Oda, R. Counteranion effect on micellization of cation- ic gemini surfactants 14-2-14: Hofmeister and other counterions. Langmuir 26, 10645-10656 (2010).

20) Rosen, M.J. Surfactants and Interfacial Phenomena. 2nd ed., Wiley, New York (1989).

21) Patial, P.; Shaheen, A.; Ahmad, I. Synthesis, characterization and evaluation of the surface active properties of novel cationic imidazolium gemini surfactants. $J$. Surfact. Deterg. 17, 253-260 (2014).

22) Tawfik, S.M. Synthesis, surface, biological activity and mixed micellar phase properties of some biodegradable gemini cationic surfactants containing oxycarbonyl groups in the lipophilic part. J. Ind. Eng. Chem. 28, 171-183(2015).

23) Li, Z.X.; Dong, C.C.; Thomas, R.K. Neutron reflectivity studies of the surface excess of gemini surfactants at the air-water interface. Langmuir 15, 4392-4396 (1999).

24) Yousefi, A. Imidazolium-based ionic liquids as modulators of corrosion inhibition of SDS on mild steel in hydrochloric acid solutions: Experimental and theoretical studies. RSC Adv. 5, 11697-11713(2015). 